\title{
TEACHING ASPECTS OF BUSINESS ANTHROPOLOGY
}

\author{
STEPHANIE A. KRAWINKLER \\ UNIVERSITY OF VIENNA, UNIVERSITY OF APPLIED SCIENCES \\ FH WIEN, UNIVERSITY OF JISHOU
}

\begin{abstract}
For a long time, anthropological field work was considered as something one can only learn and become skilled in by doing. This has been changing in the recent years and methodological trainings gained more importance. The niche of business anthropology has been growing and more structured teaching has been offered. In this paper, I explore aspects of teaching organizational anthropology to three different groups: anthropology students, business students and non-anthropological professionals. They have various needs and require different foci in their training. I aim at highlighting some of the aspects needed for successfully passing on business anthropological knowledge.
\end{abstract}

\section{Introduction}

Anthropology training primarily takes place at universities, be it at undergraduate, graduate or PhD-level. For a long time, anthropology field work was considered as something one can only learn and become an expert in through practice. Little guidance was provided during curricula (teaching) about how to conduct field work. This has changed in the recent years as methodological trainings gained more structure.

In this paper, I focus on the skills and competences of an anthropological niche: business anthropology. Besides being a small sector of applied anthropology, business anthropology covers a wide variety of fields ranging from organizational anthropology to design anthropology and consumer focused anthropology.

Business anthropological skills are not only taught to anthropologists but are also taught to, for example, business and design students. Besides, through training at an academic level, anthropological knowledge is 
passed on by consultants and business anthropologists to their co-workers and clients in various settings ranging from on-the-job-training to particular trainings. I aim at highlighting some aspects of teaching business anthropology to these different target groups.

The materials for this paper result from a literature review, my experiences of teaching anthropology, business and tourism students and my research as well as my consultancy practice. Moreover, I draw from discussions with fellow business anthropologists in person and online e.g. on the Anthropology \& Design Group. Hence, the focal point of this text is organization-focused anthropology and it examines the various needs of different learning groups.

\section{Base of Teaching Business Anthropology}

Business anthropologists are primarily hired because of their working styles and the benefits they bring to companies. They apply mostly qualitative approaches, providing space for the topics of the informants, they combine micro- and macro-level approaches and thereby take into account the complexity of everyday life. They defamiliarize observations and employ the anthropological perspective on business issues. In general, they expand the focus on non-work related aspects. The working style of anthropologists is "open" and they adapt to (unexpected) situations. In addition, informants with various backgrounds are usually included in the research process to enable a multi-perspective (Krawinkler, 2013).

Organization-focused anthropologists deal with a variety of topics and help to solve a range of problems, including analyzing aspects of corporate culture, work process analysis, mergers, identity questions, cross-cultural competences, diversity management, power structures, conflict solutions, group and organizational behaviour, and change management processes (Jordan, 2003; Krawinkler, 2013).

In recent years, the literature in the field of business anthropology has grown vastly. Besides the 2nd edition of Ann T. Jordan's book Business Anthropology (2013; first edition 2003), 2013 was a fruitful year regarding the release of much-anticipated comprehensive books on different aspects of business anthropology, including: de Waal Malefyt and Morais (2012), Caulkins and Jordan (2013), Gunn et al. (2013), and Tian et al. (2013). This was long overdue. This collection of state of the art books in the fields of business anthropology has enabled us to have a shared theoretical basis for business anthropology, which can be extended and passed on. 
These recent publications, in addition to corporate ethnographies published earlier, provide a good basis for what to teach people interested in business anthropology.

\section{Teaching Aspects of Business Anthropology}

The methods and theories in anthropology are diverse and extensive, and therefore, we cannot prepare the students for every single field situation. However, their toolbox and theoretical frames are going to develop further while being an active business anthropologist:

"It is sometimes difficult to learn the context and method of application to any great extent through course work in anthropology departments. A student with a serious commitment to be an applied anthropologist should expect, in addition, to their anthropological course work, course work in other departments, self-study, and practical experiences through internships and practica. (...) Applied anthropologists must expect that less of their training will fit traditional conceptions of what anthropology is. They must expect to be continually learning through their own efforts." (Van Willigen, 2002, p. 17)

This makes teaching business anthropology particularly challenging, especially since we aim to share business anthropology knowledge with various groups of interest. Besides working through existing cases and discussing the theoretical framework, it is necessary to equip future business anthropologists with the skills to gather data within organizations and make the analysis useful to the informants.

From experience, through reflection about these experiences, and from the lessons learnt, learners (students or clients) remember more and build up a profound know-how:

"[T]he experience of the learner occupies central place in all considerations of teaching and learning. This experience may comprise earlier events in the life of the learner, current life events, or those arising from the learner's participation in activities implemented by teachers and facilitators. A key element of experience-based learning (...) is that learners analyse their experience by reflecting, evaluating and reconstructing it (sometimes individually, sometimes collectively, sometimes both) in order to draw meaning from it in the light of prior experience. This review of their experience may lead to further action." (Andresen et al., 2001, p. 225).

This concept of learning has an impact on how to design lectures and trainings. When exchanging ideas on how to teach business anthropology 
with other colleagues, the conclusion is often that it is crucial for students to experience business anthropology in action.

\section{Target Groups}

Teaching designs (content and methods) depend on the audience's preskills, goals and resources in terms of time and accessibility to potential research fields. In the following, I describe aspects of teaching organizational-focused business anthropology to anthropology students, to business students and to paying participants, i.e. managers and consultants. Teaching know-how for the first two cases are mostly based on my own experiences as a student of anthropology, and as a lecturer of anthropology and business students. Aspects of teaching to paying participants are illustrated using an example of colleagues in the Netherlands that organize a business anthropology curriculum.

\section{Anthropology Students}

Despite their different backgrounds and interests, most people who aim to become anthropologists, share a number of characteristics: (a) they are curious to understand how the world(s) work and the reasons behind behaviour of people; (b) they emphasize the big picture; (c) they have the capabilities to handle large data sets and make sense of these using systemic approaches; and (d) change is a steady constant in the life of anthropologists (even if they conduct anthropology at home) and their work is very people-orientated and hence, involves a lot of interaction with strangers (Strang, 2009).

The following observations are taken from my experience of being a student of business anthropology and from later on teaching business anthropology to anthropology students. In addition, it is also fed by talks with colleagues such as at the meeting: "Why the world needs anthropologists. New fields for applied anthropology in Europe" organized among others by the EASA Applied Anthropology Network in Amsterdam in November 2013.

One of the main challenges for anthropology students is to adjust their communication to the addressees: there is a need to sell anthropology research, to gain access to companies, and to communicate results to the informants. Hence, they need a certain language and a clear communication of benefits and aims. The end product is not a lengthy descriptive ethnography, but it must fit the reading habits and available time of the 
addressees and therefore, in many cases have the format of a PowerPoint presentation or some posters.

This includes the challenges of knowing and specifying one's own skills, clarifying the benefits for the organization, negotiating access, having the role of "studying up" and providing feedback on the results. The first one should not be a big task, however the constant training of self-reflection learned through the years has led many anthropologists to a rigour against oneself and it seems to have made it difficult to aggregate one's competences. Hence, both in business anthropology lectures and at conferences, there have been vivid discussion and a strong focus on clarifying the skills of anthropologists and their benefits to organizations.

However, there have been attempts to provide a summary of the skills of anthropologists, for instance by Riall Nolan (2003). He approached this question by analyzing the main responsibilities and tasks an anthropology graduate student has usually carried out by the time s/he graduates.

Figure 1 Skills of Anthropologists (Nolan, 2003, p. 76, slightly adapted)

\begin{tabular}{|l|l|}
\hline $\begin{array}{l}\text { Graduate Student } \\
\text { Responsibilities }\end{array}$ & Skills acquired by doing these things \\
\hline Course work & $\begin{array}{l}\text { Self management skills. Digesting and interpreting } \\
\text { large quantities of unfamiliar material. Presenting } \\
\text { this material concisely in written and oral form. } \\
\text { Dealing with challenge and criticism. Defending } \\
\text { opinions and conclusions in a professional and } \\
\text { graceful manner. }\end{array}$ \\
\hline Fieldwork & $\begin{array}{l}\text { Entering a new situation and crafting a positive role } \\
\text { within it. Absorbing a large amount of new } \\
\text { material very quickly. Applying research and } \\
\text { problem-solving skills to specific projects and } \\
\text { achieving positive results. Working in teams with } \\
\text { diverse others to create outcomes that go beyond } \\
\text { individual abilities. Dealing with ambiguity and } \\
\text { uncertainty, coupled with pressure to perform. }\end{array}$ \\
\hline $\begin{array}{l}\text { A dissertation or } \\
\text { project }\end{array}$ & $\begin{array}{l}\text { Managerial skills, including defining a goal, setting } \\
\text { interim objectives, developing a timetable, } \\
\text { organizing information and resources. Writing } \\
\text { skills. Research skills. Presenting complex material } \\
\text { succinctly. Dealing with stress and overload. }\end{array}$ \\
\hline
\end{tabular}




\begin{tabular}{|l|l|}
\hline Teaching & $\begin{array}{l}\text { Organizing material and ordering concepts. } \\
\text { Presentation skills and methods. Motivating } \\
\text { learners, assessing the performance of others, and } \\
\text { applying rewards and sanctions Working to a tight } \\
\text { schedule. Dealing with questions and complaints. }\end{array}$ \\
\hline Other & $\begin{array}{l}\text { Proposal writing for grants or scholarships. } \\
\text { Presentation of material and ideas in professional } \\
\text { conferences. Writing articles for publication. }\end{array}$ \\
\hline
\end{tabular}

Building upon this list, he breaks the aspects down into knowledge and skills needed to perform the tasks, summarizing them in a number of competences:

Figure 2: List of Competences (Nolan, 2003, pp. 77, adapted)

\begin{tabular}{|l|l|}
\hline Competency & Skills acquired in graduate school \\
\hline Finding out things & Survey techniques \\
& Interview techniques \\
& Participant observation strategies \\
& Data recording techniques \\
& Dealing with uncertainty, ambiguity, and the \\
& unknown \\
\hline Analyzing and learning & Quantitative data analysis \\
& Qualitative data analysis \\
& Performing under time pressure \\
& Linking data from diverse sources, discovering \\
& patterns and order \\
& Making sense of complexity \\
& Translating data from one cultural frame into \\
& information in another cultural frame. \\
\hline Communicating things & Communication with diverse individuals \\
& Communication across diverse cultures \\
& Tailoring messages and styles to different \\
& cultural requirements. \\
& Report writing for diverse audiences. \\
& Oral and written presentations \\
& Interpersonal skills, e.g., persuasion, tact, and \\
& knowing when to shut up \\
& Negotiation skills \\
& Advising skills \\
& Making complex information accessible and \\
& understandable \\
\hline & \\
\hline
\end{tabular}




\begin{tabular}{|c|c|}
\hline $\begin{array}{l}\text { Planning and designing } \\
\text { things }\end{array}$ & $\begin{array}{l}\text { Identifying problems, issues, and opportunities } \\
\text { Deciding on relevant and appropriate goals and } \\
\text { objectives } \\
\text { Devising culturally appropriate methods and } \\
\text { strategies for implementation } \\
\text { Identifying and marshalling needed resources } \\
\text { Dealing with the priorities and issues of } \\
\text { diverse groups }\end{array}$ \\
\hline Managing things & $\begin{array}{l}\text { Managing time: yours and others' } \\
\text { Budget preparation and monitoring } \\
\text { Supervision of personnel } \\
\text { Delegation } \\
\text { Teamwork } \\
\text { Operating under pressure } \\
\text { Operating without supervision } \\
\text { Troubleshooting and problem solving } \\
\text { Demonstrating leadership and management } \\
\text { Collaborating } \\
\text { Coordinating } \\
\text { Motivating others to perform }\end{array}$ \\
\hline Judging things & $\begin{array}{l}\text { Learning quickly } \\
\text { Making judgements from different cultural } \\
\text { perspectives } \\
\text { Synthesizing information } \\
\text { Evaluation methods }\end{array}$ \\
\hline Self-management & $\begin{array}{l}\text { Self-motivation } \\
\text { Self-discipline } \\
\text { Initiative } \\
\text { Creativity } \\
\text { Focus } \\
\text { Meticulousness } \\
\text { Stamina } \\
\text { Independence } \\
\text { A sense of humour } \\
\text { Grace under pressure } \\
\text { Focusing for a long time on a single thing } \\
\text { Working under deadlines } \\
\text { Thinking on your feet }\end{array}$ \\
\hline
\end{tabular}


Teaching business anthropology often includes building awareness and self-confidence on the skills mentioned in Figure 2. In addition, it is necessary to make students familiar with the business language and some organizational theories. Most teaching formats used in business anthropology include a mini-research-project that requires the students to conduct a field trip and interact with the business world. Thereby, it covers all the phases of the process from designing a project, negotiating access, conducting the research, analyzing the data and presenting the results in an applicable way.

\section{Business Students}

Different challenges emerge when teaching business anthropology to business students. From my experience teaching students in the fields of human resource management, tourism and international management, the taught anthropological insights can increase their awareness of complexity of social realities. Even though, the classes I taught did not carry the term (business) anthropology in their titles, the curricula always offered the opportunity - and in most times I was explicitly asked by the head of department - to add the anthropological knowledge and perspective. A major focus, besides enlarging the perspectives (e.g. gender, ethnicity, power structure, values and norms), was exercising the differentiation between observation and interpretation.

These challenges of pluralism and self-reflection are also described by Bastide (2011, p. 65):

"HumSci... students would be relatively new to the discipline and consequently, would need time and exposure to accept the pluralistic, polysemic answers.(...) HumSci students were forced to reorganise, recombine, their existing understandings. Anthropology, a "wordy", selfreflective exercise, was in stark contrast with the frames, schemes and models given by their more familiar, and more scientific, disciplines."

To enable students to understand quickly how valuable observing and interpreting is, it is crucial to get them out of their classic, daily way of thinking. One exercise I have used consistently at the beginning of a class on organizational behaviour for first-year BA students, is the following.

A fortnight before the lecture starts, I ask them to bring an item with them in the first unit that represents them well. Note that at that time, these students have just started their term and therefore do not know each other. When we meet the first time, they are asked to place that item on a table. Shortly after, they receive the task to pick one unknown item from the 
table, and then take a piece of paper and write down their description and interpretation of the particular item and of its owner. In a next step, they have to find the owner of the item and tell him/her their previous thoughts. Then the owner confirms/corrects their assumptions. The following picture shows the diversity of such a table of personal items.

Figure 3 Examples of personal items, 2013

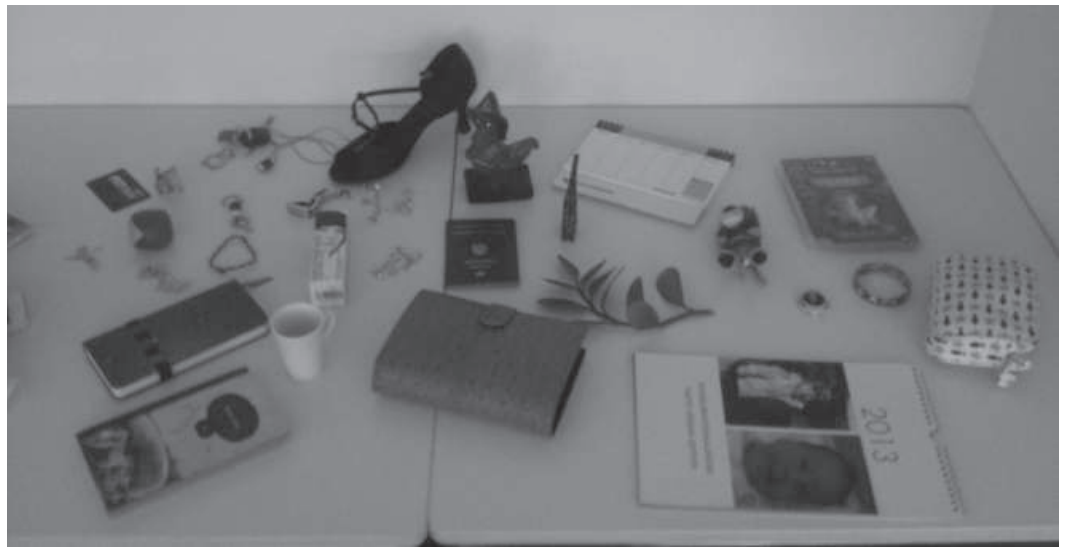

The items displayed range from small lucky charms, to objects representing hobbies, to notebooks and diaries. The task of describing and interpreting an item that belongs to a person they hardly know results, in general, in two main surprises for the students: first, how many characteristics can be ascribed to a person from a single item and second, how fitting or wrong interpretations can be. Besides being a means to increase the ties between the students and being an opportunity of exchanging personal stories with two people, it is also a great start to become more aware of the effects of the often unconscious process of observation and interpretation directly. From there on, it is easier to teach the application of (participant) observation in organizations and intercultural settings to students. Moreover, it increases the awareness on the impact of immediate interpretation and raises the willingness to exercise breaking up the process from seeing and experiencing, to describing, and to interpretation.

In addition, it challenges the students before they come to class. It is not an easy assignment for everyone to pick one item that represents themselves well. This already starts a process of reflection about oneself, which is another key focus of teaching. According to the observation of 
colleagues and my own experience, students of business related subjects are generally less trained in (self-)reflection processes than anthropology students. Besides self-reflection, observation and interpretation, other relevant fields of teaching include anthropological theories and ethics.

Tian and Walle (2008) elaborate on five factors when adapting anthropology methods to business education:

1. Include a discussion of anthropology theories and ethnographical methods in the courses.

2. Instructors should train the students in the methods and then be close at hand at the stage of field research.

3. Ethical practice should be emphasized and taught, using the guidelines of AAA, NAPA, and/or SfAA

4. Students should have knowledge of the anthropological theories (i.e. kinship, gender) and their influence on the respective field of application in business (organization-focused, consumer-focused, and product-focused).

5. The students should be taught how to analyze their data and how to present their findings.

Many of these points also apply when teaching non-anthropologists in private economy.

\section{Non-Anthropologists in the Private Sector}

It is not only anthropology and business students that benefit from studying business anthropology, but ultimately it is important that people in the private sector make use of business anthropological insights to increase their understanding and efficiency of their organizations. Teaching people in the private sector to gain these insights can either be done by including them in a research project with anthropologists, or by offering specific training to these (often) non-anthropologists by embedding it in their working life. This requires a specific structure and asks for clear benefits of added value to the participants. First of all, because they take time out of their busy schedules, and second, because they pay for this specialized type of training. In addition, one has not only to take into account that this group of learners have specific needs, but also that the focus can be on problems inside their organization.

One example of a training of this kind is the "Academie voor Organisatiecultuur" by anthropologists Danielle Braun and Jitske Kramer (Braun and Kramer, W. Y.; The following information results partially 
from personal communication with Jitske Kramer and Danielle Braun at the meeting: "Why the world needs anthropologists. New fields for applied anthropology in Europe" organized among others by the EASA Applied Anthropology Network in Amsterdam in November 2013 and further email contact in 2014). In 2014 they started to offer training curriculum on business anthropology to non-academics in the Netherlands, addressing senior managers, executives and consultants. Of the 18 participants to their training in 2014, three had a general anthropology background, while all the others were new to the field of social and cultural anthropology.

This type of training aims at enabling people to look at organizations applying an anthropological perspective, which differs significantly from the worldview of economists, business administration and psychologists. The benefits of such training is to increase the range of perspectives on various issues and to ensure that the participants are equipped with a language to discuss elements "hidden" in the cultural iceberg (Schein,2010). In the case of the "Academie voor Organisatiecultuur", issues covered include: How do cultures shape people and people shape cultures? What do these insights mean for interventions regarding culture change programs, leadership, mergers? (Kramer and Braun, 2014).

One of the main advantages of teaching people in the private sector is that they are often driven by specific problems that they have been- or are currently - confronted with. A major challenge is often that their time constraints in many cases require a short and compact training, which does not allow for a lot of time in between sessions to reflect, and limits the possibility to expose participants to the diversity of classic anthropological theories (such as kinship, rite-de-passage, power distribution, reciprocity) and to translate these into the day-to-day business reality. For example, if one looks at the organization as a community: What kinship system does one see? Where are the joking relationships, and what are the avoiding relationships? Or during change programs: who is taking care of the liminal leadership, and does that person have enough "magical power"? (Kramer and Braun, 2014; Braun and Kramer, w.Y.).

Some of the remedies to the problems mentioned above include the use of online resources and teaching material, as well as extra post-lecture material. Online learning material and other information accessible to participants from home is particularly helpful to allow self-study during and after courses, and can incorporate links, films, articles and other specialized/tailored material.

It is a challenge to make the abundance of anthropological skills and frameworks available to non-anthropologists in a way that people can apply it immediately to their specific contexts. One way to (partially) 
resolve this is to ask people to do a mini research in which they apply their acquired skills and are given the task to do a rapid cultural assessment of an unknown organization. The teaching design might also involve working on a real problem which the participant faces in his/her organization. Both have their advantages, but in either case it can rely on the network of the participants for arranging field access. More importantly it allows the participants to actively reflect with the trainers on the anthropological toolbox and the methods that they applied, as well as on the outcome of the observations and the personal experiences and feelings while conducting the fieldwork. (Kramer and Braun, 2014) However, such intervention techniques are not a particular part of the traditional anthropology toolkit and require the trainers and consultants to draw from additional education (Krawinkler, 2008).

Throughout the process, the business anthropology training can result in a certain level of confusion and uncertainty for the participants, but this is a sign of un- and re- learning. People develop a new instrument of understanding their worlds and it equips them with a language to communicate about these "invisible" things with their colleagues. Participants of business anthropological training often report that this is helpful for their personal behaviour and their interpretations in their roles as leaders and consultants.

\section{Conclusion}

No matter which type of addressees, practice seems to be key (see also the discussion in Anthropology \& Design, 2014): Getting them into the field and to practise observing, interviewing and analyzing is crucial for learning applied business anthropology. Teaching how to analyse is very often in short supply in the academic graduate years. In many cases the thesis marks the first time ever that students are confronted with the situation of making sense of data. Analysis is a matter of exercise and very often the teaching designs and resources lack the time for extended exercise and feedback. This applies to university courses, as well as to curricula for people in the private sector.

Many of the desired skills for business anthropology are similar to general anthropological ones. Guest (2003) regards skills obtained in being trained as an anthropologist useful in other areas:

"What anthropologists do in the technology industry is really not that different from what we do in more traditional engagements." (Guest, 2003, p. 259 in Strang 2009, p. 114) 
However, as briefly discussed before, it needs some additional skills as it is not only about data gathering and interpretation but also about developing and implementing change strategies.

Due to the broad span of business anthropology, business anthropologists could benefit from exchanging teaching experiences. Similar to the Teaching Material Exchange (TME) of the AAA (N.N., 2011) it would be helpful to have a joint resource of business anthropology teaching material, where teaching experiences are shared and teaching designs and materials are developed and exchanged.

\section{References}

Andresen, L., Boud, D., Cohen, R. (2001). 'Experience-based learning.' In: Foley, G. (Ed.) Understanding Adult Education and Training. Sydney: Allen \& Unwin, pp. 225-239.

Anthropology \& Design (W.Y.).http://www.anthrodesign.com/ (accessed 2014 April 10)

Anthropology \& Design (2014). Anthrodesign Digest No. 3354, Email from 2014 April 7.

Bastide, H. (2011). 'Three challenges in teaching anthropology.' Teaching Anthropology 1 (2): pp. 56-67.

Braun, D. \& Kramer, J. w Y., Academie voor Organisatiecultuur. http://academievoororganisatiecultuur.nl/ (in Dutch, accessed 2014 April15).

Caulkins, D. \& Jordan, A.T. (Eds.) (2013). A Companion to Organizational Anthropology. Malden, MA: Wiley-Blackwell Publishing Ltd.

De Waal Malefyt, T. \& Morais, R.J. (Eds.) (2013) Advertising and Anthropology. Ethnographic Practice and Cultural Perspectives. London/New York: Berg.

Gunn, W., Otto, T., Smith, R.C. (Eds.) (2012). Design Anthropology: Theory and Practice. London/New York: Bloomsbury Academic.

Jordan, A.T. (2003). Business Anthropology (1st Ed). Illinois: Waveland Press.

-. (2013).Business Anthropology (2nd Ed). Illinois: Waveland Press.

Kramer, J. \& Braun, D.2014. Email communication, 2014 April.

Krawinkler, S.A. (2008). Teilnehmende Beobachtung als Tool in der Organisationsberatung?! Dipl. Arb. Universitaet Wien (Participant observation as a tool in organizational consulting?! Master thesis. University of Vienna; in German).

-. (2013). Trust is a Choice. A Prolegomena of Anthropology of Trust(s). Heidelberg: Carl-Auer-Verlag. 
N.N. (2011). Resources. Teaching Anthropology 1(2): 122-124.

Nolan, R.W. (2003). Anthropology in Practice. Building a Career outside the Academy. Boulder/London: Lynne Rienner Publishers.

Schein, E. (2010). Organizational Culture and Leadership. San Francisco, CA: Wiley.

Strang, V. (2009). What Anthropologists Do. Oxford/New York: Berg.

Tian, R.G., Lillies, M.P., van Marrewijk, A. (2013). General Business Anthropology. Miami, FL: North American Business Press.

Tian, R. G. \& Walle, A.H. (2008). 'Anthropology and business education: Practitioner applications for qualitative method.' International Journal of Management Education 7(2) : pp. 59-67.

Van Willigen, J. (2002). Applied Anthropology: An Introduction. (3 ${ }^{\text {rd }}$ Ed.) Westport, CT: Bergin \& Garvey. 